\title{
The nature and role of experiential knowledge for environmental conservation
}

\author{
IOAN FAZEY ${ }^{1 *}$, JOHN A. FAZEY ${ }^{2}$, JANET G. SALISBURY ${ }^{3}$, DAVID B. LINDENMAYER 4 \\ AND STEVE DOVERS \\ ${ }^{1}$ Institute of Rural Sciences, University of Wales, Aberystmyth, Aberystmyth, Ceredigion $S Y 233 A L, U K,{ }^{2}$ Research Institute for Enhancing \\ Learning, School of Education, University of Wales, Bangor, Gmynedd LL57 2PX, UK, ${ }^{3}$ Biotext, 113 Hopetoun Circuit, Yarralumla, ACT 2600, \\ Australia, and ${ }^{4}$ Centre for Resource and Environmental Studies, Australian National University, Canberra, ACT 0200, Australia \\ Date submitted: 8 April 2005 Date accepted: 7 March 2006
}

\section{SUMMARY}

Understanding the nature and role of experiential knowledge for environmental conservation is a necessary step towards understanding if it should be used and how it might be applied with other types of knowledge in an evidence-based approach. This paper describes the nature of experiential and expert knowledge. It then discusses the role of experiential knowledge as a complement to scientific knowledge and explains the interplay between experiential knowledge with conservation research and practice using a simple conceptual model of how individuals learn. There are five main conclusions: (1) because experiential knowledge will always play a role in decision-making, enhancing ability to learn from experiences (including research) will have a significant influence on the effectiveness of conservation outcomes; (2) while experiential knowledge is qualitatively very different from quantitative information, both are important and complementary; (3) some experiential knowledge can be expressed quantitatively, but experiential knowledge can be difficult to isolate as single facts or propositions and qualitative methods will therefore often be required to elicit experiential knowledge; (4) because each person's expertise is unique, when using experiential knowledge the extent of a person's experience and its relevance to a particular problem need to be specified; and (5) as with any form of knowledge, there are limitations to that derived from personal experience. Synthesis and communication of research is therefore essential to help prevent erroneous thinking and, where possible, experiential knowledge should be used in conjunction with other types of information to guide conservation actions.

Keymords: evidence-based conservation, experience, indigenous knowledge, tacit knowledge, traditional ecological knowledge ${ }^{*}$ Correspondence: Dr Ioan Fazey Tel: +44 (0)1970 624471 e-mail:
irf@aber.ac.uk

\section{INTRODUCTION}

Conservation practitioners rarely apply primary research data and rely heavily on experience to make decisions (Pullin et al. 2004). This has led to calls for the application of more science, the adoption of an evidence-based approach, and the provision of mechanisms to review and disseminate research to ensure that it is accessible (Pullin \& Knight 2001; Sutherland et al. 2004). Such mechanisms are essential to help bridge gaps between conservation research and practice, to facilitate the use of the best available evidence when making decisions (Fazey et al. 2004) and to ensure that untested practices are not widely adopted simply because they have been used previously (Sutherland et al. 2004).

While environmental conservation must be informed by appropriate research, in the end, it is the practitioner who must decide how to integrate the results of research with a wide range of context-specific issues and priorities (see Sakett et al. 2000). The experience of applying conservation actions also helps to build understanding of complex environmental systems. Such systems, for the purposes of this paper, include a collection of social, economic and bio-physical components that are dynamic and have strong feedback interactions (for example Whiteman et al. 2004). Understanding of these systems may or may not have been modified by the results of research, yet the amount of experience a practitioner has about a particular environmental system can have significant implications for conservation (Woodwell 1989).

The value of experience is acknowledged in discussions about evidence-based conservation (Pullin \& Knight 2001; Sutherland et al. 2004). In these discussions, a clear distinction is made between using personal experience to apply the results of rigorous research and disseminating possibly erroneous personal experience about the effectiveness of unevaluated conservation actions. Nevertheless, in conservation, research and data are usually lacking and outcomes are often uncertain (Dovers et al. 2001). Given the complexity of environmental systems and the need for immediate action, experiential knowledge is often the best evidence that is available (for example Aswani \& Hamilton 2004; Huntington et al. 2004). There is also considerable difference between disseminating the opinions of an individual and using rigorous methods to elicit the experiential knowledge of a group of people with extensive experience of an environmental system. Finding 
ways to capture experiential knowledge and to integrate or use it with other approaches is therefore important.

A necessary first step is to understand the nature and role of experiential knowledge for environmental conservation. This paper aims to explain how the nature of experiential knowledge, which is often misunderstood, affects how it can be elicited and applied. We first describe the nature of expertise, then discuss the role of experiential and expert understanding for environmental conservation and research. The interplay of experiential knowledge with research and practice is highlighted by a conceptual model that explains how the capacity to learn from experiences influences an individual's ability to develop understanding of environmental systems. The implications of the nature and role of experiential and expert knowledge are then discussed in relation to an evidence-based approach. This paper does not aim to denigrate the value or need for appropriate and rigorous research to guide conservation practice. It is also not meant to provide a detailed account of how people learn, which we have addressed elsewhere, including a discussion about the importance of social learning (Fazey et al. 2005a).

\section{THE NATURE OF EXPERIENTIAL AND EXPERT KNOWLEDGE}

Knowledge derived from experience can broadly be separated into 'explicit', 'implicit' and 'tacit' knowledge (Nickols 2000) (Fig. 1). Explicit knowledge is that which has been articulated; implicit knowledge can be, but has not been articulated; and tacit knowledge (sensu Polanyi 1958) cannot be articulated. To describe tacit knowledge, Polanyi (1997) gives the example of being able to recognize a person's face, but without being able to explain why or how it is done.

Experiential knowledge can also broadly be separated into 'expert' and 'non-expert' knowledge (Fig. 1). Compared to less experienced individuals, experts have acquired extensive knowledge through their experiences which affects what they notice and how they organize, represent and interpret information. Some of the earliest studies of expertise compared chess masters with extremely good but less experienced players. While the chess masters almost always won the matches, researchers could find no difference between

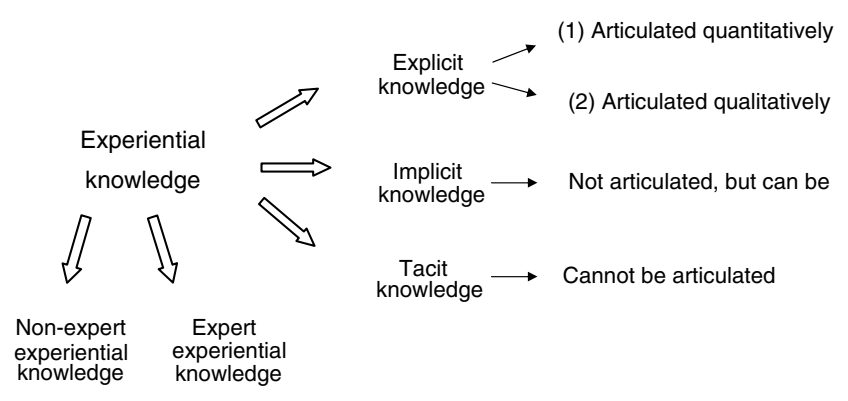

Figure 1 Different forms of experiential knowledge. the two groups in the number of moves they thought they could make, or the number of possible counter moves they anticipated from their opponents. The experts, however, appeared to be able to 'chunk' pieces of information together allowing them to recognize features and patterns not noticed by the other players (deGroot 1965).

Similarly, people who have developed a deep understanding of an environmental system through extensive experience within that system and with other systems may exhibit the hallmarks of an expert (for example Pierotti \& Wildcat 2000; Whiteman \& Cooper 2000). Such individuals may be able to recognize emergent properties and make good predictions, even though they might not be able to explain precisely how they do it. For example, recent research elicited a rich collection of knowledge from on-ground conservation managers about the management of water flows in a complex ephemeral wetland system in Australia. The 'experts' included both government-employed staff and cattle graziers with a strong interest in conservation who had many years of experience living and working within the wetland. The knowledge ranged from ecological understanding about the dynamics of the wetland, through understanding of the degree to which the wetland was threatened, to understanding about the feedback within the broader social, economic and ecological system that may have been reinforcing the conservation problems (Fazey et al. 2006).

The managers had previously applied their knowledge to many different situations, including during decisionmaking processes for releasing water allocated for maintaining environmental flows and for arguing for the need for greater commitment to the conservation of the wetland. Nevertheless, while some of the expert knowledge could be articulated, the real extent of their knowledge only became apparent in certain practical or social situations, such as in workshops where one piece of information from one manager triggered the recall of information from another (Fazey et al. 2005a). Expert knowledge cannot therefore always be reduced to isolated facts or propositions, and is considered to be much more than just memory and intelligence, or the use of general strategies (Bransford et al. 2000).

The managers were also generally reluctant to make judgements in the absence of a real-life situation and context, such as predicting the ecological response of the wetland to different hypothetical flooding scenarios. A hypothetical scenario could be described to them, but a range of factors necessary for them to make a judgement would still have been absent. This temporal-specific and situation-specific nature of expertise is well documented by educational psychologists (Barab \& Plucker 2002). In one case, researchers posed as difficult customers to present different arithmetic problems to children selling produce in markets in Brazil. The children were correct $99 \%$ of the time in the market, but their performance on the same problems in maths tests was successful only $65 \%$ of the time (Saxe 1992). This implies that a researcher asking the wrong question, or a question at the wrong time or in the wrong setting, could elicit different 
or incorrect information compared to that derived in a more appropriate real-life situation or context.

Nevertheless, this does not mean that experts will always have correct perceptions about a problem in an appropriate setting. Recent studies have demonstrated a high prevalence of large errors in the perception of corporate executives, and it is clear that effective strategic thinking does not depend on these managers having a precise understanding of the situations in which they work. In these cases, immediate knowledge does not seem to be the greatest asset that executives bring to strategic decision-making. Instead, it appears to be their ability to seek and make wise use of feedback (Mezias \& Starbuck 2003). That is, they have a good capacity to learn and respond in a flexible way to events in an uncertain world. This capacity is referred to as 'adaptive expertise' (Bransford et al. 2000).

The on-ground wetland managers in Australia provide a good example. Some of these had many years of experience with grazing practices that followed and responded to the natural and dynamic variability in water flows. The managers had developed their expertise by being adaptable and by recognizing and working with the uncertainty in the system. Their ecological knowledge about the wetland was therefore likely to be quite different from that of other stakeholders who did not live on the wetland and whose primary goal was to control and reduce the uncertainty and variability of water flow for irrigation purposes (Fazey et al. 2005a).

The value of indigenous (expert) knowledge in the conservation literature is particularly well recognized (for example Whiteman \& Cooper 2000; Horstman \& Wightman 2001; Olsson \& Folke 2001; Aswani \& Hamilton 2004). Olsson et al. (2004) highlight the difference between traditional ecological knowledge, which is an attribute of societies with a historical continuity in resource-use practice (for example Whiteman \& Cooper 2000; Horstman \& Wightman 2001), and local ecological knowledge, which is an attribute of more recently evolved resource management systems (Robertson \& McGee 2003; Fazey et al. 2006). In both cases, however, expert understanding of an ecological system is generally built through many years of observation and reflection. This learning process is greatly enhanced when individuals and/or societies are embedded in that system where they receive relatively direct ecological feedback from their actions (Whiteman \& Cooper 2000). In many cases, the development of traditional knowledge is very similar to notions of adaptive management where there is strong emphasis on feedback learning and recognition of the unpredictability of ecosystems (Berkes et al. 2000).

In general, it takes around 10 years to develop expertise of the form that is typically described in the educational literature (for example Simon \& Chase 1973). There is therefore considerable difference between expert knowledge, which exhibits a depth of understanding about an environmental system, and experiential knowledge, which may not yet have developed into expert understanding. It is also difficult to compare one expert with another for dealing with a particular conservation issue as each expert's knowledge is built from a unique set of experiences. Thus, when referring to expert knowledge, it is essential to be both clear about the basis and extent of a person's knowledge and the degree to which the knowledge is relevant to a particular circumstance.

\section{THE ROLE OF EXPERIENTIAL KNOWLEDGE}

There are two interrelated roles of experiential knowledge for environmental conservation. First, experiential knowledge can complement a scientific approach either by its integration with quantified data or by providing an alternative and separate perspective to an issue or problem. Second, tacit and implicit knowledge unavoidably guides research and practice.

\section{Experiential knowledge as a complement to scientific knowledge}

In some instances expert knowledge can be articulated quantitatively and integrated with other quantitative scientific information to provide a cost effective way of making more confident predictions (see discussions in Taper \& Lele 2004; Martin et al. 2005). For example, expert opinion proved valuable for assessing the impacts of grazing levels on bird density in woodland habitat when it was combined with survey data using a Bayesian statistical approach, especially when survey data were unavailable. When the experts agreed, predictions were found to improve considerably, and when the experts did not agree, the results were similar to those obtained when expert information was not used (Kuhnert et al. 2005; Martin et al. 2005).

Nevertheless, expert knowledge is quite different from quantitative information, making direct comparisons difficult. For example, when expert judgement was compared with computer models for predicting population trends of several hypothetical species, the opinion of the experts was slightly less accurate than the simulation models. It might have been concluded that the quantitative models were most useful. Yet, it took the experts only 1-2 hours to make the predictions compared to the 1-2 days to run the models, making the opinion of the experts a potentially cheaper and more applicable form of knowledge (McCarthy et al. 2004). Thus either form of knowledge could be considered more useful than the other depending on the circumstances to which they are to be applied.

There are serious limitations to experiential and expert understanding, and there is an extensive body of research that highlights the failure of humans to 'objectively' translate experience into 'accurate' explicit information (Sterman 2000). These failings are derived from a number of shortcomings of the human mind. People can be very defensive about changing the way they think (Argyris 1985) and it may take a long time or particularly significant events before major changes occur in understanding (Proust 2004). Humans also tend to have strong judgemental biases (Hogarth 1987), are not good at understanding complex probabilities (Anderson 2001), and are notoriously poor at learning in and 
about dynamic complex systems (Sterman 2000). Further, information given by a person may be biased, especially when there is an outcome that a person desires which may directly be affected by the information they provide (Dennis 2004).

It is therefore perhaps not surprising that implicit and tacit information tends to be given less value than information that is quantified (Boiral 2002). However, it is often forgotten that despite human failings, people still manage to function relatively effectively in a complex and ever-changing world. There are four main aspects of experiential and expert knowledge that may make it seem less valuable when compared to more accepted forms of knowledge. First, when it is made explicit, the nature and value of the knowledge changes because it is no longer linked to the rest of a person's rich implicit and tacit understanding. Second, because of the way information is stored and processed in the brain, it can be difficult for someone to qualify why or how they know something (Bransford et al. 2000). Third, experiential knowledge is difficult to recalibrate against quantitative and more accepted measures. Fourth, because experiential knowledge is based on a person's unique set of experiences (such as an ecosystem or conservation issue), the degree to which the knowledge is relevant to specific circumstances is difficult to determine. Misunderstanding its nature and not recognizing the difficulty of capturing the information is therefore at least partly why people place relatively little value on experiential and expert knowledge.

Qualitative techniques that are applied rigorously have a greater capacity to capture a larger part of the integrated and in-depth knowledge of experts than more reductionist and quantitative approaches. Thus, while they still have limitations, these approaches have had some success in helping the application of experiential knowledge to conservation. For example, farmers' knowledge of soils has been used to help make research more applicable to practice (Steiner 1998), local fishing practices in Sweden guided by local knowledge have been shown to be similar to using an ecosystem management approach (Olsson \& Folke 2001), and local knowledge has helped determine natural flood regimes to provide a benchmark for future management targets (Robertson \& McGee 2003). Expert knowledge has also been used to develop better understanding about the patterns of vegetation change and guide conservation priorities (Lykke 2000) and has helped focus policy and management on some potentially important impediments to effective conservation action (Fazey et al. 2006). The lack of value that is given to experiential and expert knowledge is also reinforced by particular cultural biases and societal views, such as established scientific practices and the need to describe experiential knowledge in Western scientific terms (Huntington 2000). Such views are resistant to change because of consistent reinforcement by the behaviour of like-minded individuals (see discussions about 'worldviews' in Kalu 2001 and Hallowell 2002). Thus, even though individuals may change their outlook through experiences, their particular societal perspective continues to reinforce their thinking behaviour. This reinforcement also occurs within academic disciplines where the papers that are read and conferences attended influence the research produced, which is then reviewed and assessed by a similar-minded group of researchers.

For example, research output from the discipline of conservation biology suggests that it is dominated by a quantitative and reductionist view. The literature published in 2001 in three prominent conservation journals predominantly comprised quantitative research $(89 \%)$, inferential statistics $(63 \%)$ and studies that focused only on biological disciplines $(87 \%)$. There were relatively few studies at broad organizational scales, such as of communities and ecosystems (25\%) (Fazey et al. 2005b). While quantitative and reductionist approaches are essential, no single view (either reductionist or synoptic) is sufficient as a basis for understanding the world (Kleine 1995). Therefore, although there are disadvantages, the nature of experiential and expert knowledge means that it can provide an alternative and/or additional perspective to that obtained using an experimental approach (Table 1).

The need for multiple conservation approaches was recognized in a seminal paper (Soulé 1985), in which conservation biology was described as needing to be 'holistic, synthetic, eclectic and multi-disciplinary', dependent on 'biological and social disciplines', and a 'mix of science and art requiring intuition as well as information'. Soulé's (1985) vision captured a general trend by Western society that has been steadily moving away from the Newtonion model of knowledge production set in a context predominantly governed by the interests of a particular academic community (Gibbons et al. 1994). Instead, in response to increased complexity, unpredictability and irregularity of society, knowledge production is increasingly being conducted in a context of application (Nowotny et al. 2001). This new mode of knowledge production has less disciplinary boundaries, is heterarchical, and is more accountable and reflexive to society (Gibbons et al. 1994).

Such changes in knowledge production are beginning to occur in many applied conservation and ecological domains, and there is increasing recognition of the need to understand how scientific research and societal practices influence each other and how this relates to achieving more ecologically sustainable practices (Kates et al. 2001). Yet, irrespective of whether such trends are perceived to be a positive or negative development, further societal shifts may be required before the value of experiential knowledge is more widely recognized and accepted.

\section{Experiential knowledge unavoidably guides research and practice}

To fully understand the way that expert knowledge influences conservation research and practice, it is necessary to understand how an individual's expertise is developed. To learn and develop expertise, individuals need to change their understanding of their place in the world and how they 
Table 1 Some of the differences between expert and experimental knowledge (from Fazey et al. 2005a).

\begin{tabular}{|c|c|c|}
\hline & Expert knowledge & Experimental knomledge \\
\hline Perspective & Greater capacity for a holistic perspective & Greater capacity for a reductionist perspective \\
\hline Historical perspective & $\begin{array}{l}\text { Has some capacity to take into account the historical } \\
\text { trajectory of something in order to make better } \\
\text { predictions about the future by interpreting the } \\
\text { present with respect to past experiences (Polanyi } \\
\text { 1958). For environmental systems, this requires } \\
\text { extensive experience of the same phenomenon } \\
\text { or system }\end{array}$ & $\begin{array}{l}\text { Has less capacity to take into account the influence of a } \\
\text { historical trajectory because predictions are based } \\
\text { only on what is occurring in the present }\end{array}$ \\
\hline $\begin{array}{l}\text { Learning from long-term } \\
\text { outcomes }\end{array}$ & $\begin{array}{l}\text { Less capacity to learn from interventions whose } \\
\text { outcomes take a long time to become apparent } \\
\text { because an individual's experience is finite } \\
\text { and relies more on immediate feedback }\end{array}$ & $\begin{array}{l}\text { Has greater capacity to learn from interventions that } \\
\text { have long-term outcomes because experiments can } \\
\text { run over long periods of time }\end{array}$ \\
\hline $\begin{array}{l}\text { Dealing with confounding } \\
\text { factors }\end{array}$ & $\begin{array}{l}\text { Has less capacity to deal with confounding factors } \\
\text { when trying to distinguish between cause and } \\
\text { effect }\end{array}$ & $\begin{array}{l}\text { Has greater capacity to deal with confounding factors } \\
\text { when trying to distinguish between cause and effect }\end{array}$ \\
\hline Accessibility & $\begin{array}{l}\text { Difficult for others to access and pick up because } \\
\text { it is can be inarticulate (tacit) or very difficult to } \\
\text { articulate (implicit) }\end{array}$ & $\begin{array}{l}\text { Easier for others to access and pick up because it is } \\
\text { formalized and made explicit }\end{array}$ \\
\hline Requirement & $\begin{array}{l}\text { Requires experimental knowledge as a check and } \\
\text { balance to ensure accurate connections between } \\
\text { cause and effect }\end{array}$ & $\begin{array}{l}\text { Requires expert knowledge to identify appropriate } \\
\text { questions, interpret results and maintain a more } \\
\text { holistic perspective }\end{array}$ \\
\hline
\end{tabular}

perceive it (Fazey \& Marton 2002). To better understand this learning process, cognitive psychologists often take the view that people understand the world by constructing working representations. That is, people construct 'mental models' from their observations and experiences, which then shape thoughts and actions (O'Connor \& McDermott 1997). These models may also change following new experiences. While the concept of having a working representation does not fully capture the dynamic learning process, it does allow an arbitrary boundary to be drawn around a person's understanding about a particular environmental system or conservation issue that occurs at a particular point in time.

If people are effective learners, then they have greater capacity to develop expert understanding. Figure 2 explains how an individual's level of expertise in learning from new experiences influences their potential to change their mental model and develop their understanding of an environmental system. To understand Figure 2, it is easiest to begin with the variable 'ability to change mental model'. With a new experience, as the potential for change increases, dogmatic commitment to an existing model becomes less likely. The ability of an individual to change their understanding of an environmental system increases, allowing the identification of questions of which the individual may previously have been unaware. This, in turn increases their potential to re-evaluate their current mental model, closing the feedback loop (Fig. 2, R1).

As a person's understanding of an environmental system changes, their capacity to build a new or modify an existing formal theory increases. The act of making implicit theories explicit by building a formal theory helps a person to: (1) identify and ask new questions (Fig. 2, R2), and (2) articulate their understanding to other people to gain different perspectives of how the system might operate (Fig. 2, R3). Theories only describe a part of the real world, and irrespective of whether they are personal or formal, they all have limitations (Lindenmayer et al. 2002). Making personal theories explicit so that they can be shared with others helps an individual to identify those limitations, which also heightens their potential to re-evaluate the accessible parts of their existing mental model.

Being a good learner primarily depends on the capacity to do two things (Fig. 2). First, taking different perspectives on an event or situation allows greater opportunities to understand an environmental system because that system can be 'seen' from different angles. That is, there will be greater potential for a person to re-evaluate their current mental model (Fig. 2). This is highlighted by research that aimed to develop participants' understandings about a complex water management problem in Switzerland. A simple role-playing board-game was used that allowed different stakeholders to put themselves in the situation of others. Not only was the technique useful for sharing perspectives, but it also allowed people to discover how their actions affected and interacted with the decisions of different stakeholders. Consequently, participants developed a much wider understanding of the dynamics of the environmental system (Pahl-Wostl \& Hare 2004).

Second, a good learner also needs to be open to the potential for an experience to change their mental model, and develop expertise in determining when it is appropriate to do so (Fig. 2). Most people are familiar with instances where their current understanding is severely challenged by new information and with the deep reluctance they feel towards 


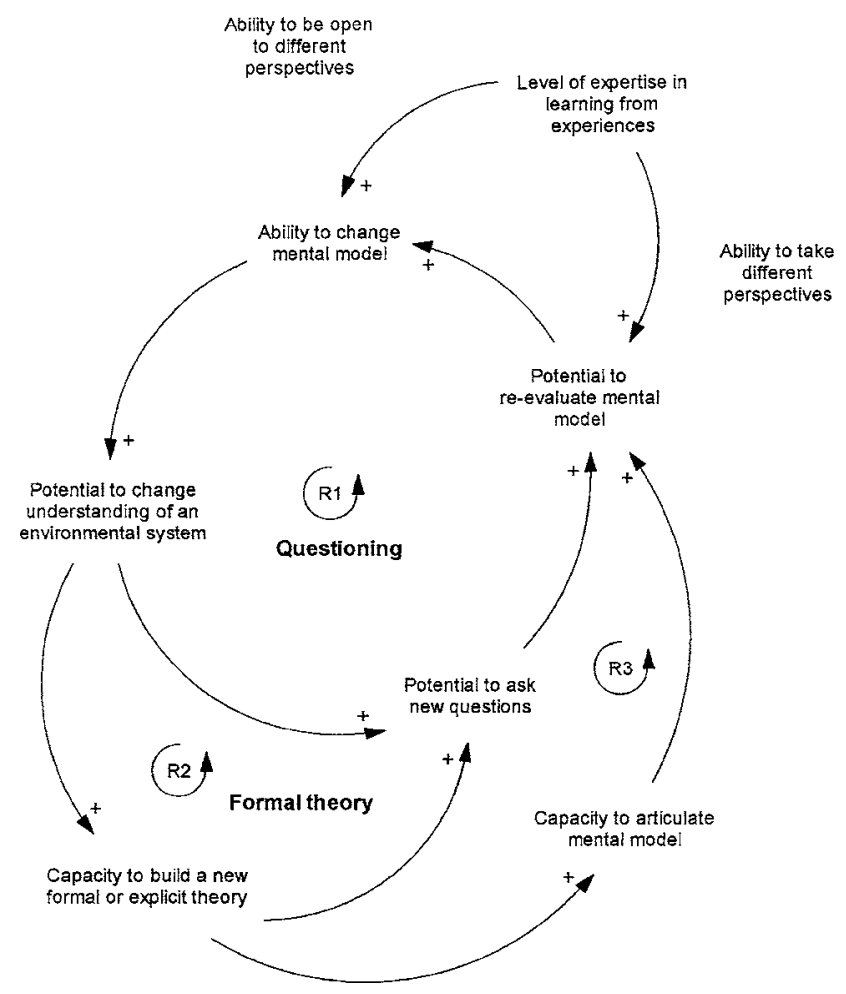

Figure 2 A conceptual model of how the level of expertise in learning from an experience influences a person's capacity to learn about environmental systems. To understand the model, it is easiest to start with the component 'ability to change mental model' (see text). The model is a causal loop diagram. The polarity of each arrow indicates whether a variable increases or decreases when the previous variable increases. For example, if the ability to change a mental model increases, then the potential to change understanding about an environmental system also increases (see Sterman 2000 for a full account of causal loop diagrams). Note that in this diagram, all the arrows are positive, creating reinforcing loops (see text).

accepting that their current understanding may be wrong. This is particularly prevalent when a person has a closed mind, where they lack an intention to change, or where they have a commitment to something that might be affected by such a change. Discipline in thinking and mindfulness of how people react to different experiences and perspectives therefore needs to be developed. People also need to become skilled in different ways of thinking, such as being empathic, flexible, inquisitive, asking pointed questions, evaluating different modes of approach and being self-reflective (Perkins $e t$ al. 2004). That is, a mind that is both adventurous and cautious in its acceptance of new information needs to be developed. Such thinking abilities are akin to those often espoused as being important for any researcher to be effective (Antonacopoulou 2004).

Understanding how expertise is developed highlights three important issues regarding the role of experiential knowledge. First, experiential knowledge unavoidably guides conservation research and practice. Over $95 \%$ of mental activity is unconscious, affecting how humans conceptualize

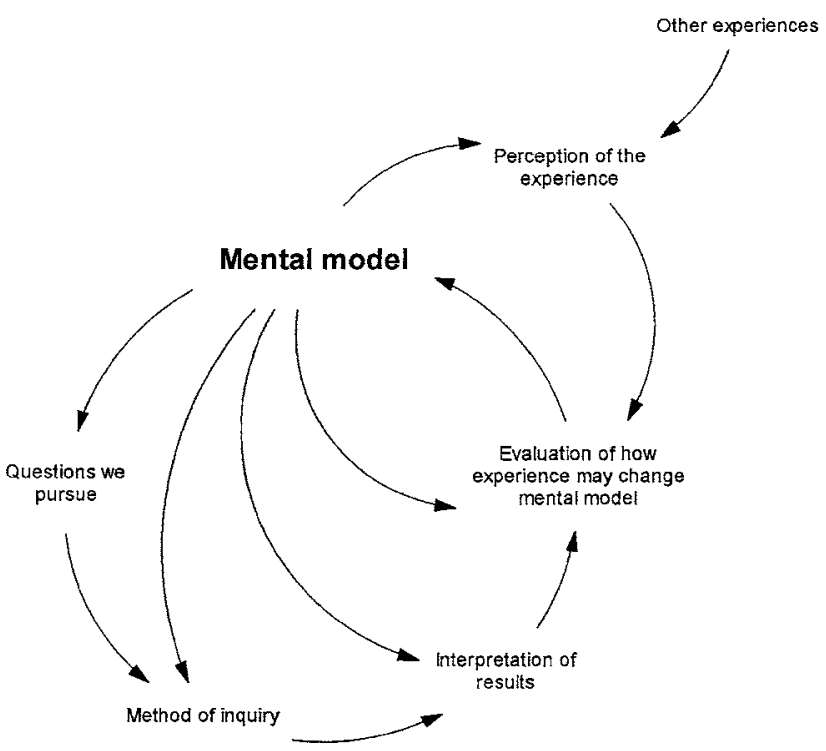

Figure 3 Mental models, which are built from observation and experiences, influence the way people perceive new experiences. This includes influences on how people perceive the experience of conducting research, such as by affecting the questions that are pursued, the methods used to design studies, the way data are collected and how they interpret the results.

all aspects of their experience (Lakoff \& Johnson 1999), and people are often unaware of how much tacit and implicit understanding influences their research and the decisions they make (Polanyi 1958). When conducting research, for example, a person's mental model influences the questions identified and pursued, the methods used to answer those questions, how the results are interpreted, and how they evaluate the impact of the research experience on their mental model (Fig. 3). The tools used to interpret the world (such as science, GIS, computers) are also designed using mental models, thereby influencing what is measured, defined and given attention to (Sterman 2000).

Experiential knowledge therefore provides the basis for identifying problems, how people go about understanding them, and what they do about them. For example, in the Solomon Islands, indigenous ecological knowledge was vital in identifying appropriate marine reserves for conserving populations of bumphead parrotfish. The indigenous knowledge helped to explain how different habitats structured the size distribution of the fish and how lunar periodicity affected fish behaviour and catch rates. It also enabled the identification of sensitive locations and habitats that were in need of protection that would otherwise have required a high level of detailed and prohibitively expensive scientific research (Aswani \& Hamilton 2004).

Second, the results of research, as a particular form of experience, may influence and help change current understanding. Conducting rigorous reviews and disseminating them using an evidence-based approach is particularly 
important for dispelling 'myths' about the effectiveness of certain conservation actions and for breaking the tendency to reinforce particular ways of thinking (Sutherland et al. 2004).

Third, while information from research (scientific or otherwise) may alter a person's understanding, reinforcing feedback (Fig. 2, loops R1-R3) also demonstrates how their thinking can become constrained. Even though their understanding of the system may be changing with new experiences, a person may also be reinforcing particular ways of thinking about that system, or possibly ways of thinking about the approaches used to try to improve their understanding, such as using quantitative or qualitative research methods, or a particular field-survey method. For example, census counts of bowhead whales in Alaska in the 1970s indicated there were $c$. 2000-3000 whales (Huntingdon 2000). The visual counts of migrating bowheads were from sites on high cliffs or pressure ridges in the ice, and were made on the assumption that when the pack-ice was closed, the whales stopped their migrations. However, when travelling across the ice, Eskimo whalers often came across whales which were either migrating beyond the ice flows or were breathing through cracks in the ice. The whalers challenged the counts of the scientists, and collaboration between the two groups led to the census being expanded to include aerial and acoustic survey techniques to complement the visual counts. The use of multiple techniques, which provided additional perspectives, led to a new estimate of 6000-8000 whales (Huntington 2000).

Reinforced thinking also partly explains why certain formal theories with significant limitations can remain unquestioned for a long time. Initially, a theory may open up new insights into the way people think, but then their eyes begin to see the world through the lens of that theory. The acceptance of the theory can also be reinforced because of people's tendency to read or publish in certain journals, present at particular types of conferences, and work with people who generally think and feel the same way. The application of Island Biogeography Theory to terrestrial systems for conservation is a good example. Despite its many limitations, the theory was widely accepted for many years and generated a plethora of related research. It has been suggested, however, that a return to what researchers were thinking about before the theory's inception is needed to avoid both constrained ways of thinking and ineffective conservation policies (Haila 2002).

There is therefore a complex interplay between experiential knowledge and the results of research. Tacit and implicit knowledge guides what and how research is conducted, while the process and results of the research provide a particular form of experience that may help people change their understanding. Research may also help them break particular, possibly erroneous ways of thinking. However, because future understanding is guided by what has already been experienced, particular views can be reinforced. This means that understanding about an environmental system or conservation issue may continue to develop, but that it may only be developing from a particular perspective and in a particular direction. Understanding will therefore be constrained if there is a dogmatic commitment to a specific research method, theory, paradigm or societal outlook.

The strongest defence against people's current mental models driving them down particular thinking paths is their expertise in learning (Fig. 2). Taking a step back and finding new ways of looking at an issue reduces the tendency to assume that the way something is perceived is the only way, or that it is the same way others perceive it. Taking different perspectives gives greater potential for re-evaluating understanding of something, and if people are open to how those perspectives might influence their mental representations of the world, their potential to be willing to develop understanding also increases.

\section{WHY EVIDENCE-BASED CONSERVATION AND EXPERT KNOWLEDGE ARE BOTH IMPORTANT}

We agree with the proponents of evidence-based conservation (Pullin \& Knight 2001; Sutherland et al. 2004) that a revolution is required in the way conservation is conducted, and that an evidence-based approach is a good way to begin facilitating better environmental learning. The evidence-based approach is particularly important for three reasons: (1) it encourages the review of what is often disparate and inaccessible research; (2) it provides a forum for the dissemination of synthesized research; and (3) it sets a precedent for reviewing current information, formulating plans, and then evaluating and disseminating the outcomes (Fazey et al. 2004; Sutherland et al. 2004). Given the high degree of dynamic complexity in environmental systems, we suggest that the strength of the approach is likely to be its capacity to facilitate greater reflection and learning from conservation interventions, rather than just its provision of detailed a priori evidence for those actions.

Through greater accessibility to the results of research, individuals are more likely to be exposed to different perspectives providing them with greater opportunity to reevaluate their mental models (Fig. 2). This helps break particular, possibly erroneous, ways of thinking (Sutherland et al. 2004). In addition, an evidence-based approach encourages individual practitioners to apply some of the principles of reflective practice by setting precedents for greater evaluation of conservation actions. Such reflection is vital for the development of an individual's expert knowledge (Fazey et al. $2005 a$ ). However, disseminating information is only one step towards implementation (Lomas 1993), and the effectiveness of conservation decisions will be heavily influenced by people's expertise of an environmental system because practitioners will always need to determine how to apply research results in context-specific and dynamic settings.

Compared to one person's experience of an intervention, the accumulation and dissemination of the experience of many individuals could be particularly powerful (Sutherland et al. 2004). However, accumulating information often loses the detail of what, how and why an intervention was applied. In particular, a practitioner may have a certain degree of 
understanding about the historical trajectory of a problem, whereas predictions from experiments are mostly based on a snapshot of what is currently occurring (Table 1). Because environmental systems are complex, 'learning-bydoing' approaches like adaptive management (Walters \& Holling 1990) or the application of local expert knowledge will also be required (Millennium Ecosystem Assessment 2005). Nevertheless, such approaches would benefit from, and are complementary to, evidence-based practice (Fazey et al. 2004).

Because studies with rigorous experimental designs are easier to systematically synthesize than studies that lack strict control, the amount of available evidence that is reviewed can become skewed towards interventions that make better experiments. For example, in medicine there is often considerable evidence that has been reviewed for the use of pharmaceuticals, compared to more individually tailored and holistic approaches such as counselling or cognitive therapy to treat mental illness (R. Woodward, personal communication 2004). To avoid similar problems, environmental conservation will therefore need ways to integrate different types of knowledge to ensure that it does not become preoccupied with management solutions that make good experimental studies when more novel or holistic ways are required to treat the real causes of the problem (Fazey et al. 2004).

To make sure that people do not head down particular thinking paths that reduce their acceptance of other approaches, people need to regularly take a step back, take different perspectives and be open to how something might change their way of thinking. That is, individuals will need to rely both on expertise in being able to learn from experiences and on their individual expert understanding of environmental systems to maintain focus on what is important. Without such understanding, much of conservation research would 'spread into a desert of trivialities' (Polanyi 1958).

Knowledge management has become a major industry (McManus et al. 2003), and many organizations are trying to find ways to capture the implicit and tacit knowledge of employees before they move elsewhere (Holloway 2000). For example, in medicine, intranet systems are increasingly being used to capture, share and reflect on implicit and organizational information (Mimnagh 2002). Finding better ways to disseminate implicit knowledge could also benefit many conservation organizations. Mechanisms for the management of explicit knowledge may need to be in place for implicit knowledge management to work (Mimnagh 2002). Thus, provided that the value of implicit knowledge is recognized, an evidence-based approach could be a useful springboard for a much wider revolution that includes the development and sharing of experiential knowledge.

\section{CONCLUSIONS}

There are five main conclusions arising from this paper about the nature and role of experiential and expert knowledge for conservation. First, experiential knowledge derived from a mixture of research, work, educational, and personal experience will always play an important role in decisionmaking, and will have a major influence on the way environmental systems are studied and managed. Developing the capacity to learn better from experiences (including learning from the results of research) and the ability to reevaluate ways of thinking will have a significant influence on the effectiveness of conservation outcomes.

Second, tacit and implicit knowledge is often considered to be less important than quantitative or explicit information. However, while an expert's knowledge is qualitatively very different from scientific knowledge both are important and inherently linked. The depth of understanding that the different types of knowledge provide, and the manner and context in which they are applied, will largely determine their comparative value.

Third, some experiential knowledge can be articulated quantitatively and integrated with other quantitative information. However, experiential knowledge can often be difficult to isolate as single facts or propositions, and it loses much of its value because it is then no longer linked to the rest of the person's implicit or tacit understanding. Thus other, qualitative methods will be required to elicit and communicate much of the knowledge that can be made explicit.

Fourth, there is no single definition of an 'expert'. It is difficult to compare one expert with another for dealing with a particular conservation issue as each expert's knowledge is built from a unique set of experiences. It also takes considerable time to develop the form of expertise that is typically discussed in the educational literature. When referring to expert knowledge, it is therefore important to be clear about (1) the basis and extent of this knowledge, and (2) the degree to which the knowledge is relevant to a particular circumstance.

Finally, as with any form of knowledge (including science), experiential knowledge has limitations and there is much potential for people to generate erroneous thinking. This means that (1) effective ways of synthesising and disseminating research are essential to increase the potential for individuals to re-evaluate their current ways of thinking, and (2) wherever possible, an experientially-based approach should be applied in conjunction with other approaches.

An evidence-based approach is important for increasing emphasis on reviewing the effectiveness of conservation management. In addition to making research more accessible to the wider conservation community, the process could also facilitate personal development and understanding about environmental systems through increased reflection. Yet, to give rise to better understanding, academics and practitioners will also need to be open to the perspective that it is a worthwhile endeavour to find appropriate ways to elicit, communicate and share experiential knowledge.

\section{ACKNOWLEDGEMENTS}

D. Fazey, J. Fischer and L. Gibbs kindly provided comments on previous versions of the manuscript. The paper would also 
not have been possible without discussions with B. Newell, K. Proust, R. Reid, and R. Woodward. We would also like to thank four anonymous reviewers who provided useful comments. Ioan Fazey was supported by an Endowment for Excellence Scholarship from The Australian National University.

\section{References}

Anderson, J.L. (2001) Stone Age minds at work on 20th century science: how can cognitive psychology inform conservation biology? Conservation Biology in Practice 2: 20-27.

Antonacopoulou, E. (2004) On the virtues of practicing scholarshipA tribute to Chris Argyris, a 'timeless learner'. Management Learning 35: 381-395.

Argyris, C. (1985) Strategy, Change, and Defensive Routines. Boston, USA: Pitman.

Aswani, S. \& Hamilton, R.J. (2004) Integrating indigenous ecological knowledge and customary sea tenure with marine and social science for conservation of bumphead parrotfish (Bolbometopon muricatum) in the Roviana Lagoon, Solomon Islands. Environmental Conservation 31: 69-83.

Barab, S.A. \& Plucker, J.A. (2002) Smart people or smart contexts? Cognition, ability, and talent development in an age of situated approaches to knowing and learning. Educational Psychologist 37: 165-182.

Berkes, F., Colding, J. \& Folke, C. (2000) Rediscovery of traditional ecological knowledge as adaptive management. Ecological Applications 10: 1251-1262.

Boiral, O. (2002) Tacit knowledge and environmental management. Long Range Planning 35: 291-317.

Bransford, J.D., Brown, A.L. \& Cocking, R.R. (2000) How People Learn: Brain, Mind, Experience, and School. Washington, DC, USA: National Academy Press.

deGroot, A.D. (1965) Thought and Choice in Chess. The Hague, Netherlands: Mouton.

Dennis, B. (2004) Statistics and the scientific method in ecology. In: The Nature of Scientific Evidence, ed. M.L. Taper \& Lele, S.R. Chicago, USA: University of Chicago Press.

Dovers, S., Norton, T.W. \& Handmer, J.W. (2001) Ignorance, uncertainty and ecology: key themes. In: Ecology, Uncertainty and Policy: Managing Ecosystems for Sustainability, ed. J.W. Handmer, T.W. Norton \& S.R. Dovers, pp. 1-25. Harlow, UK: Pearson Education Limited.

Fazey, J.A. \& Marton, F. (2002) Understanding the space of experiential variation. Active Learning in Higher Education 3: 234250.

Fazey, I., Fazey, J.A. \& Fazey, D.M.A. (2005a) Learning more effectively from experience. Ecology and Society 10(2) [www document] URL http://www.ecologyandsociety.org/vol10/iss2/art4/

Fazey, I., Fischer, J. \& Lindenmayer, D.B. (2005b) What do conservation biologists publish? Biological Conservation 124: 63-73.

Fazey, I., Proust, K., Newell, B., Johnson, B. \& Fazey, J. (2006) Eliciting the implicit knowledge and perceptions of on-ground conservation managers of the Macquarie Marshes. Ecology and Society (in press).

Fazey, I., Salisbury, J.G., Lindenmayer, D.B., Maindonald, D. \& Douglas, R. (2004) Can methods applied in medicine be used to summarize and disseminate conservation research? Environmental Conservation 31: 190-198.
Gibbons, M., Limoges, C., Nowotny, H., Schwartzman, S., Scott, P. \& Trow, M. (1994) The Nem Production of Knomledge: The Dynamics of Science and Research in Contemporary Societies. London, UK: SAGE Publications.

Haila, Y. (2002) A conceptual genealogy of fragmentation research: From island biogeography to landscape ecology. Ecological Applications 12: 321-334.

Hallowell, A.I. (2002) Obijwa ontology, behaviour, and worldview. In: Readings in Indigenous Religion, ed. G. Harvey, pp. 17-49. London, UK and New York, USA: Continuum.

Hogarth, R. (1987) Fudgement and Choice. Chichester, UK: John Wiley and Sons.

Holloway, P. (2000) How to protect knowledge from walking out the door. Workforce Magazine [www document]. URL http://www.workforce.com/archive/article/22/07/11.php

Horstman, M. \& Wightman, G. (2001) Karpati ecology: recognition of Aboriginal ecological knowledge and its application to management in north-western Australia. Ecological Management and Restoration 2: 99-109.

Huntington, H.P. (2000) Using traditional ecological knowledge in science: methods and applications. Ecological Applications 10: 1270-1274.

Huntington, H.P., Suydam, R.S. \& Rosenberg, D.H. (2004) Traditional knowledge and satellite tracking as complementary approaches to ecological understanding. Environmental Conservation 31: 177-180.

Kalu, O.U. (2001) The sacred egg: worldview, ecology and development in West Africa. In: Indigenous Traditions and Ecology: the Inter Being of Cosmology and Community, ed. J.A. Grim, pp. 225-248. Cambridge, USA: Harvard University Press.

Kates, R.W., Clark, W.C., Corell, R., Hall, J.M., Jaeger, C.C., Lowe, I., McCarthy, J.J., Schellnhuber, H.J., Bolin, B., Dickson, N.M., Faucheux, S., Gallopin, G.C., Grubler, A., Huntley, B., Jager, J., Jodha, N.S., Kasperson, R.E., Mabogunje, A., Matson, P., Mooney, H., Moore, B., O'Riordan, T. \& Svedin, U. (2001) Environment and development - sustainability science. Science 292: 641-642.

Kleine, S.J. (1995) Conceptual Foundations for Multidisciplinary Thinking. Stanford, USA: Stanford University Press.

Kuhnert, P.M., Martin, T.G., Mengersen, K. \& Possingham, H.P. (2005) Assessing the impacts of grazing levels on bird density in woodland habitat: a Bayesian approach using expert opinion. Environmetrics 16: 717-747.

Lakoff, G. \& Johnson, M. (1999) Philosophy in the Flesh: The Embodied Mind and its Challenge to Western Thought. New York, USA: Basic Books.

Lindenmayer, D.B., Manning, A.D., Smith, P.L., Possingham, H.P., Fischer, J., Oliver, I. \& McCarthy, M.A. (2002) The focal-species approach and landscape restoration: a critique. Conservation Biology 16: 338-345.

Lomas, J. (1993) Diffusion, dissemination, and implementation: who should do what? Annals of the Nem York Academy of Sciences 703: 226-235; discussion 235-227.

Lykke, A.M. (2000) Local perceptions of vegetation change and priorities for conservation of woody-savanna vegetation in Senegal. Journal of Environmental Management 59: 107120.

Martin, T.G., Kuhnert, P.M., Mengersen, K. \& Possingham, H.P. (2005) The power of expert opinion in ecological models using Bayesian methods: impact of grazing on birds. Ecological Applications 15: 266-280. 
McCarthy, M.A., Keith, D., Tietjen, J. Burgman, M.A., Maunder, M., Master, L., Brook, B.W., Mace, G., Possingham, H.P., Medellin, R., Andelman, S., Regan, H., Regan, T. \& Ruckelshaus, M. (2004) Comparing predictions of extinction risk using models and subjective judgement. Acta Oecologica 26: 6774.

McManus, D.J., Snyder, C.A. \& Wilson, L.T. (2003) The knowledge management imperative [www document]. URL http://www.knowledgeharvesting.org/documents/The\%20Knowledge\%20Management \%20Imperative.pdf

Mezias, J.M. \& Starbuck, W.H. (2003) Studying the accuracy of managers' perceptions: a research odyssey. British fournal of Management 14: 3-17.

Millenium Ecosystem Assessment (2005) Ecosystems and Human Well-being: Synthesis. Washington DC, USA: Island Press.

Mimnagh, C.J. (2002) Towards capturing implicit knowledge: a practical application of intranet development. Advances in Clinical Knomledge Management 5 [www document]. URL http://www. openclinical.org/docs/ext/workshops/ackm5/absMimnagh.pdf

Nickols, F. (2000) The knowledge in knowledge management. In: The Knomledge Management Yearbook 2000-2001, ed. J.W. Cortada \& J.A. Woods, pp. 12-21. Boston, USA: ButterworthHeinemann.

Nowotny, H., Scott, P. \& Gibbons, M. (2001) Re-thinking Science: Knomledge and the Public in an Age of Uncertainty. Cambridge, UK: Polity Press.

O'Connor, J. \& McDermott, I. (1997) The Art of Systems Thinking. London, UK: Thorsons.

Olsson, P. \& Folke, C. (2001) Local ecological knowledge and institutional dynamics for ecosystem management: a study of Lake Racken Watershed, Sweden. Ecosystems 4: 85-104.

Olsson, P., Folke, C. \& Berkes, F. (2004) Adaptive comanagement for building resilience in social-ecological systems. Environmental Management 34: 75-90.

Pahl-Wostl, C. \& Hare, M. (2004) Processes of social learning in integrated resources management. Fournal of Community and Applied Social Psychology 14: 193-206.

Perkins, D., Jay, E. \& Tishman, S. (2004) A dispositional theory of learning [www document]. URL http://learnweb.harvard. edu/alps/thinking/docs/merrill.htm

Pierotti, R. \& Wildcat, D. (2000) Traditional ecological knowledge: the third alternative (commentary). Ecological Applications 10: 1333-1340.

Polanyi, M. (1958) Personal Knomledge: Tomards a Post-critical Philosophy. London, UK: Routledge \& Kegan Paul.
Polanyi, M. (1997) Tacit knowledge. In: Knowledge in Organizations, ed. L. Prusak. Boston, USA: Butterworth-Heinemann.

Proust, K. (2004) Learning from the past for sustainability: towards an integrated approach. Ph.D. thesis, Centre for Resource and Environmental Studies, Australian National University, Canberra, Australia.

Pullin, A.S. \& Knight, T.M. (2001) Effectiveness in conservation practice: pointers from medicine and public health. Conservation Biology 15: 50-54.

Pullin, A.S., Knight, T.M., Stone, D.A. \& Charman, K. (2004) Do conservation managers use scientific evidence to support their decision-making? Biological Conservation 119: 245-252.

Robertson, H.A. \& McGee, T.K. (2003) Applying local knowledge: the contribution of oral history to wetland rehabilitation at Kanyapella Basin, Australia. Fournal of Environmental Management 69: 275-287.

Sackett, D.L., Strauss, S.E., Richardson, W.S., Rosenberg, W. \& Haynes, B. (2000) Evidence-Based Medicine: How to Practice and Teach EBM. Edinburgh, UK: Churchill Livingstone.

Saxe, G.B. (1992) Studying children's learning in context: problems and prospects. The Fournal of the Learning Sciences 2: 215-234.

Simon, H.A. \& Chase, W.G. (1973) Skill in chess. American Scientist 61: 394-403.

Soulé, M.E. (1985) What is conservation biology? Bioscience 35: $727-$ 734.

Steiner, K.G. (1998) Using farmers' knowledge of soils in making research results more relevant to field practice: experiences from Rwanda. Agriculture Ecosystems and Environment 69: 191-200.

Sterman, J.D. (2000) Business Dynamics - Systems Thinking and Modeling for a Complex World. Boston, USA: McGraw Hill.

Sutherland, W.J., Pullin, A.S., Dolman, P.M. \& Knight, T.M. (2004) The need for evidence-based conservation. Trends in Ecology and Evolution 19: 305-308.

Taper, M.L. \& Lele, S.R. (2004) The Nature of Scientific Evidence: Statistical, Philosophical and Empirical Considerations. Chicago, USA: University of Chicago Press.

Walters, C.J. \& Holling, C.S. (1990) Large-scale management experiments and learning by doing. Ecology 71: 2060-2068.

Whiteman, G. \& Cooper, W.H. (2000) Ecological embeddedness. Academy of Management Fournal 43: 1265-1282.

Whiteman, G., Forbes, B.C., Niemela, J. \& Chapin, F.S. (2004) Bringing feedback and resilience of high-latitude ecosystems into the corporate boardroom. Ambio 33: 371-376.

Woodwell, G.M. (1989) On causes of biotic impoverishment. Ecology 70: $14-15$. 